\section{Aluminum phosphide-induced esophageal stricture: an unusual complication}

Aluminum phosphide is a solid fumigant pesticide used for preserving grains. We report here on six cases of aluminum phosphide poisoning presenting as esophageal strictures.

Six patients (three men and three women; mean age 25.3 years, range $12-56$ ) ingested tablets of Celphos (aluminum phosphide, weight $3 \mathrm{~g}$, diameter $15 \mathrm{~mm}$ ) with suicidal intentions (66.6\%) or accidentally (33.3\%). All of the patients vomited out the partially dissolved tablet 15 min later. They were managed with symptomatic treatment. All of the patients had progressive dysphagia for the following $10.5 \pm 5.43$ days. Barium swallow examinations revealed strictures $0.8 \pm 0.22 \mathrm{~cm}$ long in the mid-esophagus, with proximal dilation (Figure 1). Endoscopy showed circumferential ulcerations and strictures at $26.8 \pm 3.12 \mathrm{~cm}$ (Figure 2 ). Biopsies from the ulcers showed infiltration with neutrophils, lymphocytes, and fibroblasts. All of the patients underwent dilation treatment with Savary-Gilliard dilators 6 weeks after ingesting the Celphos tablets, at 2-week intervals. They received $7.66 \pm 7.06$ dilation sessions. One patient developed a tracheoesophageal fistula [1] during the course of the illness while receiving treatment in the dilation program.

Acute aluminum phosphide poisoning has been associated with a high mortality rate. All of these patients survived because they had ingested previously exposed tablets [2] and vomited the partially dissolved tablets. The tablets did not reach the stomach, where the gastric acid helps to release phosphine.

The mechanism of stricture development may have been adhesion of the tablet at the most narrow portion of the esophagus. Celphos liberates phosphine gas when it comes into contact with a moist surface. Phosphine leads to the inhibition of cytochrome oxidase and catalase [3], leading to hypoxic cell damage, lipid peroxidation [4], and protein denaturation due to the generation of oxygen free radi-

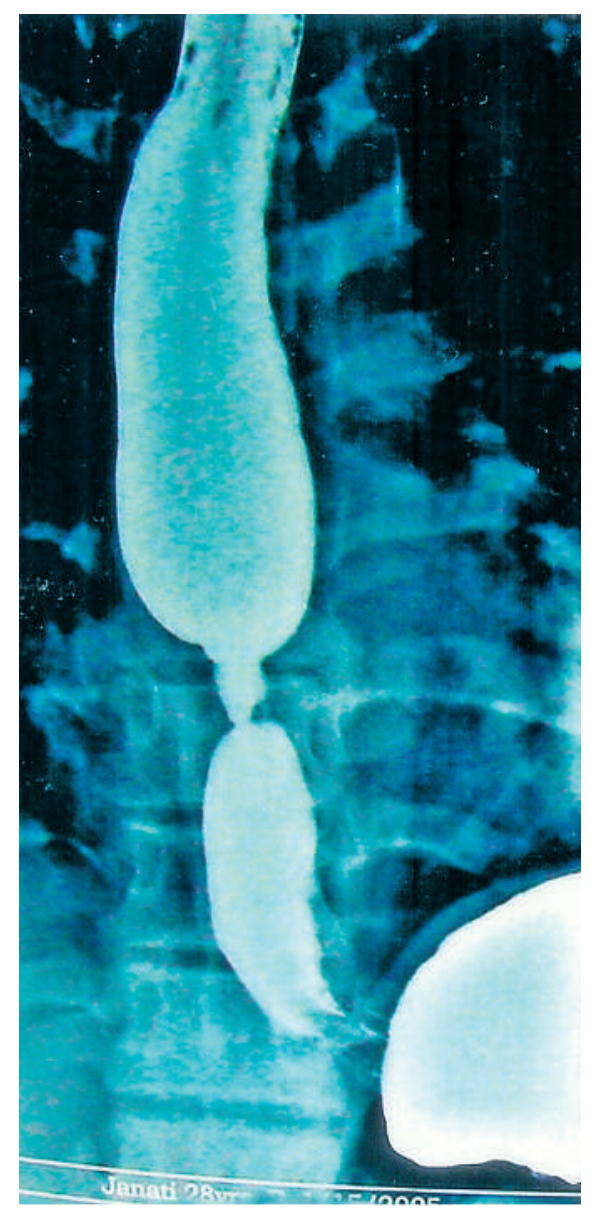

Figure 1 A barium swallow examination, showing a $1-\mathrm{cm}$ long stricture with proximal dilation of the esophagus.

cals. This leads to an inflammatory response, followed by healing with fibrosis. Two patients with esophageal strictures due to aluminum phosphide poisoning have been reported on in the recent literature [5].

Aluminum phosphide ingestion thus causes esophageal stricturing that is resistant to endoscopic dilation.

Endoscopy_UCTN_Code_CCL_1AB_2AC_3AD

\section{S. Nijhawan, M. Rastogi, M. Tandon,} A. Mathur, R. R. Rai

Dept. of Gastroenterology, Sawai Maan Singh Medical College and Hospital, Jaipur, India.

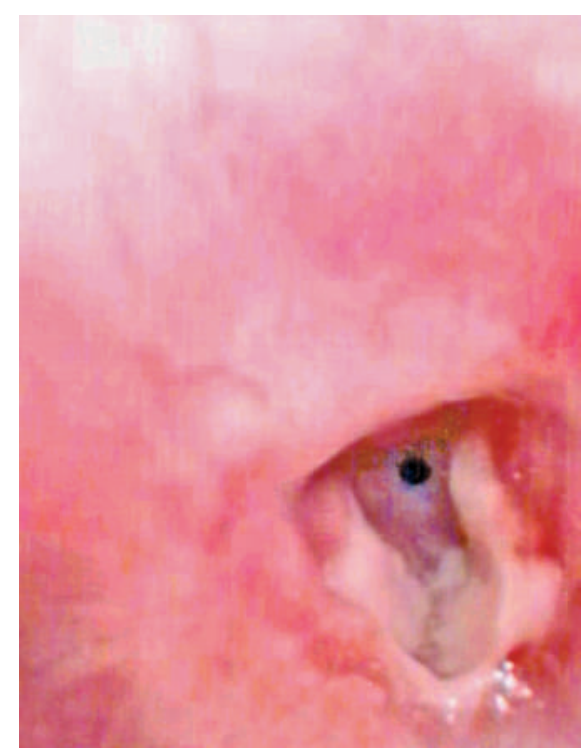

Figure 2 The endoscopic appearance of the esophageal stricture, showing circumferential ulceration with narrowing of the lumen.

\section{References}

${ }^{1}$ Tiwari J, Lahoti B, Dubey K et al. Tracheoesophageal fistula: an unusual complication following Celphos poisoning. Indian J Surg 2003; 65: $442-444$

${ }^{2}$ Chugh SN, Arora V, Kaur S, Sood AK. Toxicity of exposed aluminium phosphide. J Assoc Physicians India 1993; 91: 569-570

${ }^{3}$ Chefurka W, Kashi KL, Baid KP. The effect of phosphine on electron transport in mitochondria. Pest Biochem Physiol 1976; 6: 65

${ }^{4}$ Chugh SN, Mittal A, Seth S, Chugh K. Lipid peroxidation in acute aluminium phosphide poisoning. J Assoc Physicians India 1995; 43: 265-266

${ }^{5}$ Kapoor S, Naik S, Kumar R et al. Benign esophageal stricture following aluminium phosphide poisoning. Indian J Gastroenterol 2005; $24: 261-262$

\section{Corresponding author}

\section{S. Nijhawan, M.D.}

112, Panchsheel Enclave

Gokul Bahi Bhatt Marg

Durga Pura

Jaipur 302017

India

Fax: +91-0141-2560994

E-mail: dr_nijhawan@yahoo.com

DOI: 10.1055/s-2006-944637 